\begin{tabular}{|l|l|}
\hline & \\
PUCRS & HUMANIDADES \\
\hline http://dx.doi.org/10.15448/2178-3748.2020.2.37461 & $\begin{array}{l}\text { Oficina do historiador, Porto Alegre, v. 13, n. 2, p. 1-10, jul.-dez. } 2020 \\
\text { e-ISSN: 2178-3748 }\end{array}$ \\
\hline
\end{tabular}

SEÇÃO: ARTIGOS

\title{
História e condição feminina na obra A Carne (1888), de Júlio Ribeiro
}

\author{
History and female condition in the novel A Carne (1888), by Júlio Ribeiro
}

\author{
Joachin Azevedo Neto ${ }^{1}$ \\ orcid.org/0000-0001-9880-8988 \\ joachin.azevedo@upe.br
}

Ediene Gomes da Silva ${ }^{1}$

orcid.org/0000-0003-1044-0555 ediene_g@hotmail.com

Recebido em: 26/3/2020. Aprovado em: 3/8/2020. Publicado em: 21/12/2020.
Resumo: Este artigo analisa o romance $A$ Carne, publicado pela primeira vez em 1888, a partir de um diálogo entre literatura ficcional com estudos de Foucault, Didi-Huberman e Mary Del Priori, bem como por meio de análises da recepção crítica da obra em determinados periódicos cariocas. Foi também realizada uma abordagem comparativa entre $A$ Carne e outros romances naturalistas do mesmo período, com ênfase na crítica social presente nessa seara literária. O escritor Júlio Ribeiro, portanto, por mais que tenha elaborado um romance repleto de temáticas eróticas para interpretar a condição feminina, não conseguiu romper completamente com os padrões senhoriais de sua época.

Palavras-chave: Júlio Ribeiro. Naturalismo. História das mulheres.

Abstract: This article analyzes the novel $A$ Carne, published for the first time in 1888, from a dialogue between this fictional narrative with studies by Foucault, Didi-Huberman and Mary Del Priori, as well as through analysis of the critical reception of the work in certain Rio periodicals. A comparative approach was also carried out between $A$ Carne and other naturalistic novels from the same period, with an emphasis on the social criticism present in this literary field. Therefore, the writer Júlio Ribeiro, no matter how much he elaborated a novel full of erotic themes to interpret the female condition, did not manage to completely break with the manorial standards of his time.

Keywords: Júlio Ribeiro. Naturalism. Women's History.

\section{Introdução}

Júlio César Ribeiro Vaughan nasceu em 10 de abril de 1845, na cidade de Sabará, Minas Gerais. Tornou-se jornalista e gramático, fundou três jornais que não obtiveram sucesso, além de ser colaborador em outros periódicos, nos quais divulgava suas ideias republicanas e anticlericais que eram vistas como afronta à igreja. Publicou seus dois romances Padre Belchior de Pontes, escrito em dois volumes (1876-1877) e A Carne (1888). Esse último causou uma grande polêmica de cunho moral e religioso. $A$ obra acabou sendo classificada pelos críticos como um texto obsceno e próprio da baixa literatura.

Durante toda a sua carreira, Ribeiro dividiu opiniões entre críticos e admiradores de suas obras. Publicada em 1881, a Gramática portuguesa é considerada uma das suas criações intelectuais mais relevantes. O estudo foi motivo de elogios entre grandes autores e filólogos da época, como retrata o seguinte trecho, retirado do artigo de Valentim Magalhaes. No
Artigo está licenciado sob forma de uma licença Creative Commons Atribuição 4.0 Internacional. 
texto, publicado no periódico carioca A Semana, em 1885, Magalhães destacou o possivel reconhecimento internacional dessa obra e fez uma verdadeira apologética de seu autor:

A outra obra de Julio Ribeiro, que lhe fez solida e respeitável a reputação de estudioso e reformador é a sua estimadissima Grammatica, que em Portugual como no Brazil, é considerada a mais scientifica e racional em face dos actuaes progressos da glottica e dos estudos antrophologicos e linguisticos, e talvez sem pár em ambos os países.

\section{[...]}

Era de um homem d'esses que estávamos sentindo falta. De um observador recto e inabalável, imparcial e sereno, de um critico independente e libérrimo, sem gargalheiras partidárias nem atilhos de pequeninas conveniências; de um corajoso até a insolencia, de um justo até a crueldade, de um sincero até a grosseria; de um escritor que escrevesse por civismo - é que de há muito necessitávamos (MAGALHÃES, 1885, p. 2).

No que corresponde à carreira de jornalista na imprensa, Júlio Ribeiro ganhou notoriedade devido aos comentários irônicos e combativos que tecia. $O$ autor de $A$ Carne expressou a sua opinião através de críticas e de polêmicas, por meio de um estilo de escrita ferino. Recurso retórico usado para dar a impressão, entre os leitores, de que pouco se importava com a recepção de seus artigos. Com uma linguagem direta e até considerada ofensiva, Ribeiro conquistou fãs que admiravam sua coragem e conhecimento acadêmico, mas também agremiou grandes críticos no campo profissional e pessoal. Segundo ilustra o jornal O Mercantil, em publicação anônima de 1890, o romancista era tido como um sujeito extremamente desagradável: "E eram artigos violentos os que the atirava ao público, cheios quase sempre de um vocabulário terrivel, que traduzia todo o seu ódio e caracterisavá o seu espirito por demais vingativo" (JÚLIO, 1890, p. 1).

Por outro viés, muitos o admiraram enquanto uma personalidade magnética de seu tempo. Virtudes como a sua independência de pensamentos e comportamentos eram evocadas por comentadores de diversos matizes. Considerado polêmico e destemido, Ribeiro usa a imprensa para reafirmar o seu posicionamento de escritor independente.
Em 1885, rebateu críticas contra a sua obra que foram publicadas no Diário Mercantil no mesmo ano. Em coluna intitulada "Cartas Sertanejas", desafiou tanto grupos políticos monarquistas, afirmando a sua adesão às ideias republicanas, bem como confrontou o público leitor do periódico ao defender seu estilo próprio de escrita:

Escrevo para satisfazer minha própria actividade, e não para agradar ao público. Se achar quem pense como eu penso, muito bem: terei companheiro. Se não, ficarei só. Não há nisso mal: de ha muito habituei-me a não contar com os favores da opinião, e a procura em mim próprio a approvação dos meus actos (RIBEIRO, 1885, p. 7).

Entretanto, A Carne, publicado em 1888, é a sua obra de maior repercussão e a que the rendeu severas críticas de autores como José Verissimo, Rocha Pombo e o padre Senna Freitas. O citado pároco foi pivô de um intenso debate público sobre moral com o escritor. Essa rusga acabou resultando na publicação, em 1934, de uma póstuma antologia de textos intitulada Uma polêmica célebre. Essa compilação foi analisada pela historiadora Célia Silveira, no artigo "Fama e infâmia: leituras do romance A carne". Segundo a autora, o embate entre Ribeiro e Senna Freitas vai além do campo literário e se trata de um conflito de visões sobre as ligações entre religiosidade e principios éticos. A obra reúne os artigos publicados pelos autores na imprensa da época. Nesses artigos, o Padre Senna Freitas intitula o livro de Ribeiro de A Carniça. Em resposta, Ribeiro publica uma série de artigos com o título "O urubu: Senna Freitas".

Ainda conforme destaca Célia Silveira:

O ponto nodal da polêmica situou-se no plano da moral, com a acusação de que Ribeiro colocava no mesmo patamar os sentimentos dos homens e as necessidades do mundo animal. Senna Freitas, "boquiaberto com tal imprudência de Júlio Ribeiro", observou que, em A Carne. o "amor é cio, e nada mais". O padre português se escandalizou sobretudo porque a conduta da protagonista do romance é considerada natural pelo autor (SILVEIRA, 2010, p. 197).

O romance A Carne, portanto, foi classificado pela crítica literária como uma obra pertencente à seara do naturalismo. Inspirado no pioneirismo 
de Zola, essa escola artística busca retratar a condição humana a partir das concepções científicas, típicas do século XIX, de factualidade e situação tipica. Ou seja, os escritores adeptos dessa vertente estética acreditavam estar imunes às tentações do estilo romântico que primava pela criação ficcional de personagens exóticas e enredos inverossímeis. O crítico Alfredo Bosi, em História concisa da literatura brasileira, adverte para as contradições que encontra em sua leitura dessa tendência narrativa: "a procura do típico leva, às vezes, o romancista ao caso e, daí, ao patológico" (BOSI, 2006, p. 171) Na sua opinião, o naturalismo, portanto, preservou uma sobrevida do romantismo ao "perscrutar o excepcional, o feio, o grotesco", considerando ainda que "esse comprazimento em descrever situações, hábitos e seres anômalos tem um lastro na cultura ocidental que transcende as divisões da história literária" (2006, p. 172).

\section{Condição feminina e naturalismo}

Em linhas gerais, os autores naturalistas deram preferência em ambientar as suas tramas ficcionais em contextos urbanos e em um tipo de postura técnica e "neutra" em face do destino das personagens. A pretensa indiferença dos naturalistas diante dos mais diversos dramas enfrentados por toda sorte de criaturas, que encarnavam arquétipos, como o rico falido; a moça ambiciosa e interiorana; o português lascivo; ou a negra sensual, por exemplo, tem fortes implicações históricas. Trata-se de uma performance narrativa que visa atestar a impotência desses artistas diante de forças sociais deterministas e implacáveis: filosofia oficial que vigorou não apenas em escolas literárias, mas também no âmbito acadêmico em todo o Ocidente, de meados do século XIX até periodo bem recente.

O romance $A$ Carne apresenta, portanto, como protagonista Helena Matoso, conhecida por todos como Lenita: uma bela jovem, educada com esmero pelo seu pai. Fato que a fez nutrir grande interesse pelas ciências, diferenciando-se de outras moças da vizinhança, para as quais a maior preocupação era conseguir um bom casamento.
O conhecimento intelectual e a condição financeira foram fatores importantes na construção da consciência de si da personagem. Lenita não encontrava razões para casar-se, contrariando as convenções sociais da época.

Seu pai passou a se sentir culpado por ter oferecido um alto grau de instrução para a moça, pois estava convicto de que essa era a causa da rejeição da hipótese do casamento por parte de Lenita:

$$
\begin{aligned}
& \text { Lopes Mattoso ia despedindo os pretendentes } \\
& \text { com grandes affectaçôes de magua - que } \\
& \text { a menina não queria casar, que era uma ori- } \\
& \text { ginal, que elle bem a aconselhava, mas que } \\
& \text { era trabalho baldado, mil cousas emfim que } \\
& \text { suavisassem a repuisa (RIBEIRO, 1888, p. 5). }
\end{aligned}
$$

Lenita chegou aos vinte e dois anos conservando o mesmo pensamento. Entretanto, a morte de seu pai the causou profundo abalo emocional. Solteira e órfã, foi acolhida na fazenda de um antigo amigo da família: o coronel Barbosa. Foi nessa localidade que a moça apresentou sintomas que despertaram a preocupação de todos ali residentes: indisposição, surtos nervosos, gritos e falta de ar. O que the ocasionou frequentes internações hospitalares.

Ao longo da narrativa, é possivel identificar trechos nos quais a personagem passa por um processo de transformação pessoal. Se antes foi dotada de razão e autocontrole, Lenita passa a agir como uma mulher irracional que não domina os seus desejos. O narrador de $A$ Carne não faz distinções entre a confusão de sentimentos, traço típico do comportamento humano, com os instintos dos animais: "sentia-se ferida pelo aguilhão da carne, espolinhar-se nas concupiscências do cio, como uma negra boçal, como uma cabra, como um animal qualquer... era a suprema humilhação" (RIBEIRO, 1888, p. 18). Nesse contexto, a protagonista do romance descobre a sua sexualidade a partir de alucinações, inquietações físicas e psicológicas que a conduziam a constantes desmaios e convulsões. Essa sexualidade aflorada, exposta e clinicada, foi tida, por médicos e tutores, como sintomas de doença, loucura e necessidade de casar-se.

O filósofo Michel Foucault, no primeiro volu- 
me da obra História da sexualidade, intitulado "A vontade de saber", analisou como uma série de discursos médicos, eugenistas e higienistas, produzidos no século XIX, foram usados não apenas para estabelecer verdades científicas em torno do sexo, mas também para disciplinar a prática no contexto de consolidação das sociedades industriais. A ideia de atividade sexual saudável foi gradativamente associada à finalidade reprodutiva. Escolhas e condutas sexuais fora desse padrão normativo foram consideradas patologias que ameaçavam a integridade da saúde e moral públicas. Sobretudo, das mulheres.

Ainda de acordo com Foucault (1988, p. 66-67), a burguesia europeia construiu um discurso de poder, estabelecido como verdade, que atrelou a sexualidade aos conceitos de pecado, sujidade, patologia, desvio, interdito, tabu, vergonha etc. Esse discurso atendeu aos interesses de grupos sociais privilegiados, ligados a instituições médicas e religiosas, interessados na repressão do assunto como forma de controle coletivo. Em meio a esse panorama histórico, a sexualidade passou a ser um tema sobre o qual não se deveria falar abertamente para não estimular a curiosidade. o comportamento sexual dos indivíduos passa a ser algo que deve ser clinicado por médicos ou confessado aos padres pelos penitentes. De um lado, discursos cientíicos alertavam as pessoas sobre uma série de doenças associadas ao desregramento sexual e, de outro, a Igreja elenca a castidade como uma grande virtude espiritual.

Sendo assim, classificar e clinicar a histeria feminina foi um grande desafio para a medicina de fins do século XIX. Foi Charcot, enquanto psiquiatra do hospital parisiense da Salpêtrière, a partir de 1862, e depois como professor de anatomia patológica, em 1872, que criou registros fotográficos de pacientes histéricas e diferenciou essa enfermidade da epilepsia. O citado médico francês e seus discipulos criaram um verdadeiro catálogo de diferentes formas de histeria a partir da observação de várias pacientes que foram submetidas a uma série de usos teatrais do corpo, a pose, para a máquina fotográfica. Esses arquivos visuais da histeria transformaram a doença em espetáculo clínico, com imagens e legendas para as diferentes formas das crises: convulsões, letargia, delírios, contrações musculares, delírios etc. A inegável plasticidade fotográfica do trabalho de Charcot contribuiu para a disseminação da representação nosológica do grande ataque histérico. Essas imagens clinicas foram interpretadas por diferentes artistas como sintomas não de uma patologia, mas de experiências místicas (DIDI-HUBERMAN, 2007).

Lenita é caracterizada como uma personagem histérica e desequilibrada, no começo do enredo de A Carne. Torna-se maldosa e se compraz ao torturar animais, castigar e assistir castigos que eram aplicados aos escravos da fazenda. A personagem passa a apreciar a sensação de se sentir senhora do sofrimento alheio. A mesma tinha instantes de reflexões sobre as suas atitudes e o seu corpo, chegando a acreditar que estava doente:

\begin{abstract}
Analysava a crise hysterica, o erotismo, ocesso de crueldade que tivera. Estudava o seu abatimento actual irritadiço, dissolvente, cortado de desejos inexplicaveis. Surprehendia-se amiudadas vezes a pensar sem o querer no filho do coronel, nesse homem jâ maduro, casado, a quem nunca $v$ i $r$ a; sentia que lhe pulsava apressado o coraçâo quando fallavam nelle em sua presença. 'E concluia que aquillo era um estado pathologico, que a minava um mal sem cura (RIBEIRO, 1888, p. 54).
\end{abstract}

Quando Manoel, filho do coronel Barbosa, chega na fazenda do pai para ali morar e superar o recente divórcio, Lenita se decepcionou ao deparar-se com um homem ríspido, frio e que não lhe deu a atenção esperada. Diante da situação inesperada, a jovem conclui que não havia razão em tentar seduzir um homem que não lhe tratou de maneira gentil e mostrou-se indiferente. Como resposta, Lenita cogita adotar um estilo de vida completamente hedonista:

Si era a necessidade organica, genesica de um homem que a torturava, porque não escolher de entre mil prócos um marido forte, nervoso, potente, capaz de satisfaze-la, capaz de sacia-la?

E si um lhe não bastasse porque não conculcar preconceitos ridiculos, porque não tomar dez, vinte, cem amantes, que lhe matassem o desejo, que the fatigassem o organismo? 
Que the importava a ella a sociedade e as suas estupidas convenções de moral? (RIBEIRO, 1888, p. 62)

Em várias passagens da obra, Lenita reflete sobre a sua condição social privilegiada e planeja formas de se satisfazer sexualmente sem nenhum compromisso. A personagem estava consciente que era diferente das outras mulheres que conheceu. A aceitação ou a rejeição de um indivíduo condiziam com regras impostas por uma elite sem nenhuma justificativa plausivel, mas por pura convenção social. Sendo assim, Lenita "teria amantes, porque não? Que the importavam a ella as murmurações, os dizquedizques da sociedade brazileira, hypocrita, maldizente. Era moça, sensual, rica - gosava. Escandalizavam-se, pois que se escandalizassem" (RIBEIRO, 1888, p. 65).

A trama romanesca ganha um novo sentido na medida que a personagem consegue se aproximar de Manoel Barbosa e, lentamente, vai se construindo uma relação também de afeição entre o casal de amantes. Lenita identifica traços protetores no comportamento de Manuel, ao passo que ele se encanta pela consistente formação intelectual da moça. Entre encontros fortuitos, passeios e conversas, os dois partilham da paixão em comum pelas teorias darwinistas e as mais recentes descobertas cientificas. No entanto, Manoel tentava sempre reprimir o afeto que desenvolveu por Helena, pois julgou impossivel assumir uma relação amorosa entre ele, um homem bem mais velho e agora divorciado, com uma jovem que tinha idade para ser sua filha.

Lenita acaba obcecada por Manoel, chegando a ter delírios eróticos quando tinha contato com ou sentia seu cheiro. Quando entra pela primeira vez no quarto do amante, a moça entra em um estado de êxtase ao sentir o odor dele no travesseiro:

Sentia quase o mesmo que sentira na noite de hallucinação com o gladiador, um prazer mordente, delirante, atroz, com extranhas repercussões sympathicas, mas incompleto, falho. Trincou nos dentes a cambraia da fronha, gemendo, ganindo em contrações espasmódicas (RIBEIRO, 1888, p. 85).
A narrativa ousada e detalhada chocou o público e foi tema de intensas discursões entre críticos literários, leitores e estudiosos que apontavam a obra como uma crítica de Júlio Ribeiro à sociedade brasileira do século XIX. O escritor teve, portanto, o intuito de contestar a tradição religiosa e moral que tratava a sexualidade feminina como algo destinado apenas à reprodução e ao instinto materno. Helena Matoso representa a imagem literária de uma mulher desinibida, elitista, dona de seu corpo e de ideias vanguardistas em meio a um tórrido e proibido caso amoroso. Porém, temáticas abordadas por Ribeiro como o sexo fora do casamento, os desejos eróticos, o amor livre e, principalmente, a histeria como traço comportamental patológico dessa mulher acaba reforçando um determinismo que endossa estigmas e estereótipos femininos.

A historiadora Mary Del Priore, em História das Mulheres no Brasil, esclarece que, em fins do século XIX, a representação literária de personagens femininas com comportamentos patológicos, motivados pela descoberta da sexualidade, era um tema comum e tinha a finalidade pedagógica de legitimar discursos clinicos sobre determinadas condutas sociais. A medicina da época caracterizou a histeria como sintoma típico de suposta fragilidade psicológica das mulheres. A erotomania era considerada uma doença que atingia os nervos e os sentidos das mulheres, retirando a autonomia sobre seus corpos e pensamentos. A solução, portanto, defendida por vários médicos, higienistas, magistrados e formadores de opinião é que essas mulheres precisavam ser amparadas pela instituição do casamento. Segundo a autora: "em geral, as personagens histéricas são enfermas, órfãs de mãe, e é sugerido que a causa da enfermidade é a quebra do quadro familiar. A cura está no casamento, na procriação, na aceitação das normas institucionalizadas" (DEL PRIORE, 2004, p. 359).

Na verdade, a temática do casamento também é figurada nas páginas do romance. Lenita, sempre por meio de posturas audaciosas, revela os seus sentimentos para o cúmplice. A confissão da moça despertou em Manoel reflexões críticas sobre a definição de matrimônio. Porém, o per- 
sonagem teme os julgamentos e perseguições que sofreria caso decidisse casar-se com Lenita:

Casar com Lenita não podia, era casado. Tomala por amante? Certo que não. Preconceitos intimos não os tinha: para elle o casamento era uma instituição egoistica, hypocrita, profundamente immoral, soberanamente estupida. Todavia era uma instituição velha de milhares de annos, e nada mais perigoso do que arrostar, contrariar de chofre as velhas instituições: ellas hão de cahir, sim, mas com o tempo, com a mesma lentidão com que se formaram, e não de chofre, como um relampago. A sociedade estigmatizava o amor livre, o amor fora do casamento; força era acceitar o decreto antinatural da sociedade (RIBEIRO, 1888, p. 87-88).

O casamento é avaliado por Manoel como imposição de uma instituição demagoga e respaldada pela hipocrisia da sociedade ocidental. No entanto, o personagem acaba coadunando com as convenções que critica ao desistir de enfrentar a moral dominante para não perder o prestígio que detinha em um meio social abastado. Nesse sentido, A Carne reforça, nesse primeiro momento narrativo, mais ainda as prédicas românticas do periodo que associavam o homem com o controle das emoções e o domínio da racionalidade, bem como reservavam para a mulher o fardo da intempestividade das paixões e dos desejos.

Contudo, em um segundo momento, o romance ganha caminhos inesperados ao Lenita encontrar antigas cartas de Manoel Barbosa para outras mulheres. Como se estivesse acordando de um transe. Helena procura raciocinar melhor sobre o seu próprio comportamento. A decepção lhe causou arrependimento de suas ações e a mudança de suas opiniões acerca das convenções sociais:

Amor que não tenda a santificar-se pela constituição da familia, pelo casamento legal, acceito, reconhecido, honrado, não é amor é bruteza animal, é desregramento de sentidos. Não, ella não amára a Barbosa, aquillo não tinha sido amor. Procurára-o, entregára-se a elle por um desarranjo organico, por um desequilibrio de funcções, por uma nevrose (RIBEIRO, 1888, p. 244).

Em linhas gerais, Helena reage às suas emoções e busca controlar as rédeas de seu destino. Se tinha escolhido, outrora, satisfazer as suas vontades sexuais com Manoel, decide findar aquela relação por ser dar conta de que não o amava. Após descobrir estar grávida, Lenita abandona a fazenda e vai para São Paulo em busca de um pai para seu filho. A moça assume o protagonismo final do romance, ao buscar uma solução que the permitisse tocar a vida sem precisar lidar com a pecha de mãe solteira. Manoel Barbosa julga Lenita e sente profunda tristeza quando descobre que outro homem estava criando o seu filho.

Embora tenha esboçado uma critica dos costumes de toda uma época e buscado colocar a protagonista Lenita em uma condição favorável, ao fim do enredo ficcional que abordou um tórrido e clandestino romance, Júlio Ribeiro acaba reforçando padrões normativos e conservadores típicos de seu tempo. Em sociedades patriarcais, o casamento é visto como essencial para manutenção da ordem social, religiosa, de uma família ideal, garantia de estabilidade e status respeitável.

Casos extraconjugais não eram bem vistos publicamente por autoridades médicas, clericais e policiais. Porém, nos bastidores da vida privada, relações clandestinas, em geral com prostitutas, eram consideradas um paliativo para aplacar a luxúria e os instintos supostamente naturais dos chefes e filhos da típica familia burguesa brasileira. Nesse universo masculino, a prostituta era um tipo social necessário para satisfazer desejos sexuais que as esposas não podiam realizar, pois a representação romântica da mulher, disseminada na época, postulava que a principal função da mulher casada era cuidar da casa, do esposo e dos filhos, devendo sempre agir de modo elegante e obediente (RAGO, 1987, p. 61-94).

A prostituta é tida como simbolo de sensualidade e atração sexual. Devido ao seu comportamento tido como amoral, personifica um adjetivo estigmatizador que poucas mulheres gostariam de receber. Conhecedora do universo sexual e dos segredos do corpo, capaz de libertar e satisfazer desejos intimos, as cortesãs tinham seu próprio padrão social de estilo. O que lhes diferenciava perante as outras mulheres. Nessa perspectiva, a filósofa Simone Beauvoir, ao analisar a condição feminina contemporânea, na obra O segundo sexo: a experiência vivida, relata que 
a aparência e a conduta definiam o perfil moral da mulher na Europa do século XIX. De acordo com esses padrões, as mulheres deveriam estar atentas para não haver um desequilibrio entre o pudor e a sensualidade.

Para a autora, seguir esse imperativo era fundamental para uma mulher ser considerada honesta e pertencente ao seio familiar:

Somente a prostituta, cuja função é exclusivamente a de um objeto erótico, deve manifestar-se sob esse aspecto único; como outrora, os cabelos côr de açafrão e as flores do vestido, boje os saltos altos, os cetins colantes, a maquilagem violenta, os perfumes pesados anunciam-lhe a profissão. A qualquer outra mulher censuram-lhe "vestir-se como uma puta". Suas virtudes eróticas acham-se integradas na vida social e não devem apresentar-se senão sob esse aspecto bem comportado (BEAUVOIR, 1967, p. 298).

Dessa maneira, as mulheres costumam ser educadas sob a normativa de que o pudor é o traço comportamental que lhes garante respeito. A mulher tida como decente não pode se comportar de qualquer modo e está cercada de objeções e regras que regem as suas atitudes, a aparência e até a forma de pensar para que não se torne um mero objeto erótico. A personagem Lenita é comparada a uma prostituta pela imprensa da época por apresentar um perfil ousado, entusiasmado com a experiência sexual. O Jornal do Commercio, em edição publicada em 7 de outubro de 1888, no Rio de Janeiro, apresenta exagerada crítica sobre a obra A Carne:

O Sr. Júlio Ribeiro tentou demonstrar a seguinte these (these aliás já muito explorada na literatura): que aquela menina prodígio, de espirito elevado, de cerebro ricamente mobiliado, podia transforma-se, como se transformou, em relés prostituta, desde que o seu organismo, desequilibrado pela nevrose, sentio-se torturada pelos desejos carnaes (BIBLIOGRAFIA, 1888, p. 1).

Exagerada porque Lenita contornou a paixão, foi embora grávida da fazenda de seu tutor e, mesmo assim, encontrou estabilidade social. Parece ser esse o principal detalhe da trama que surpreendeu os leitores e despertou, na imprensa, elogios, mas também uma série de condenações morais por parte de diversos comentadores. Outro romance naturalista brasileiro, intitulado
O cortiço, de Aluízio de Azevedo, publicado em 1890, também retratou o casamento enquanto instituição destinada a garantir a manutenção do status quo que vela pela postura socialmente submissa da mulher e mascara as transgressões que aconteciam nos bastidores da vida familiar.

Azevedo representou a vida urbana no Brasil de fim de século apontando o homem como produto do meio em que vive, denunciando contrastes econômicos, tratando da miscigenação racial, cultural e evidenciando a luta dos indivíduos para ascender de classe e, assim, conseguirem reconhecimento social. Ao apresentar um enredo que configura dramas amorosos, mentiras, traição e promiscuidade, a condição feminina é tema recorrente no livro O Cortiço, conforme pode-se perceber o seguinte trecho que se refere ao desabafo de uma personagem insatisfeita com a vida conjugal: "Desgraçadamente para nós, mulheres de sociedade, não podemos viver sem o esposo quando somos casadas; de forma que tenho de aturar o que me cahio em sorte, quer goste delle quer não goste" (AZEVEDO, 1890, p. 38).

Também na obra A Normalista, publicada em 1893, o escritor Adolfo Caminha abordou questões como o incesto, tradições familiares, gravidez fora do casamento, fantasias sexuais e outros temas considerados polêmicos. Sob a ótica regionalista, Caminha narra a história da protagonista Maria do Carmo que, chantageada, acaba violada pelo padrinho João da Mata, de quem dependia financeiramente. $O$ ato resulta em uma gravidez indesejada. Entretanto, diferente da trama consensual de Júlio Ribeiro, em A Normalista, a protagonista é colocada como objeto passivo do desejo de seu padrinho, que a persegue com chantagens psicológicas e falsas promessas. Sem alternativas, a jovem cedeu às pressões do preceptor com desprezo: "E ela não tinha remédio senão ficar quieta, imóvel, com o olhar úmido no teto, abandonada às carícias sensuais daquele homem repugnante que a perseguia como um animal no cio, mas que afinal de contas era seu padrinho..." (CAMINHA, 1893, p. 143).

Dessa maneira, o romance de Adolfo Caminha faz uso da representação da donzela inocente 
que não resiste às investidas de um homem mais experiente. Após a descoberta forçada da sexualidade, Maria do Carmo se sente culpada e recorre ao isolamento social para se preservar do escândalo público que envolveu essa relação imprópria. Entretanto, após a morte do filho durante o parto, a moça encontra um pretendente disposto a casar-se com ela, ignorando seu passado e the oferecendo um futuro reconfortante após tanto sofrimento.

Tal desfecho se assemelha ao da personagem Lenita, da obra A Carne: ambas conseguem superar os dissabores de relações sexuais e afetivas clandestinas, ao encontrarem individuos que, prontamente, as assumem enquanto esposas mesmo cientes que possuiam um passado libertino. No entanto, a aceitação da mulher na sociedade sempre se dá partir da relação estável e sacramental com um homem nessas duas narrativas.

Logo, os romances mencionados apresentam três narrativas que colocam em evidência a condição feminina no Brasil do século XIX a partir da temática da paixão, sexualidade e casamento. Temáticas exploradas em constante contato com diversos conceitos que apontam para estigmas clinicos como a histeria e a loucura ou estetizam o problema da rejeição social. Desse modo, as citadas obras de Júlio Ribeiro, Adolfo Caminha e Aluizio Azevedo são definidas como naturalistas porque narram o comportamento humano a partir de exemplos patológicos e de uma constante tensão entre a razão e as forças da natureza.

No contexto do romance $A$ Carne, os impulsos prevalecem sobre a razão humana, a natureza e os seus mistérios regem o comportamento da mulher, proporcionando coragem para viver a experiência de entrega e satisfação de seus desejos por tanto tempo guardados, mas que agora afloravam com uma intensidade classificada como erótica

A Carne, portanto, provocou debates acalorados entre a sociedade letrada do Rio de Janeiro do fim do século XIX. Entre a aprovação ou o repúdio, essas reações contribuíram para promover a curiosidade em torno de um livro tido como uma merecida afronta aos costumes morais e clericais da época ou como romance escandaloso, que comparava os desejos humanos ao comportamento irracional dos animais. No mesmo ano de sua publicação, o romance causou agitação na imprensa e diversos jornais publicaram notas sobre o conteúdo do livro. Na coluna "Bibliografia", publicada no Jornal do Commercio, em outubro de 1888, encontra-se uma análise rispida sobre essa obra. Ribeiro, que tem seu talento reconhecido pelo jornalista anônimo, sendo considerado um verdadeiro mestre da língua portuguesa, mas que falhou miseravelmente na produção do enredo naturalista de $A$ carne: "A carne é um compendio, ou antes, uma marmota de pornographia realista; encerra em suas páginas todas, mas todos os quadros vivos que os escriptores naturalistas tem inventado para dar a nota do escândalo nas suas obras" (BIBLIOGRAFIA, 1888, p. 1).

O redator sugeriu, em seu comentário, que o livro não pode ser considerado um romance ficcional. A narrativa em questão se tratava bem mais de um apanhado das opiniões pessoais de Ribeiro sobre áreas como ciência, sociedade e os costumes daquela época. Sendo, portanto, um texto literário naturalista, porém de péssima qualidade estética:

\begin{abstract}
O pessoalismo do autor da carne é excessivo, absorvente, absurdo, inacceitavel: substitue-se aos personagens, prega, disserta ex-cathedra, e até as cousas inanimadas ele parece querer transmitir o seu scientifismo, o seu modo de sentir e de pensa (BIBLIOGRAFIA, 1888, p. 1).
\end{abstract}

Júlio Ribeiro teve sua vida abreviada por complicações causadas pela tuberculose. Enquanto esteve enfermo, pediu que a imprensa o deixasse em paz e não buscou responder as especulações jornalísticas sobre o seu estado de saúde. Faleceu em 1 de novembro de 1890. Poucos dias depois, o jornal O Mercantil, em artigo anônimo intitulado "Júlio Ribeiro", somou número em face dos periódicos que divulgaram notas sobre a morte do escritor. O texto menciona sua trajetória literária polêmica e lamenta a perda do intelectual:

A maior parte dos que o conheciam esperava esse final agonizante e horrivel em que desappareceu Julio Ribeiro. De uma independência absoluta, de um grande desrespeito a tudo que fosse convenção, de uma franqueza severa, 
e por vezes brutal, elle criára inimizades em toda parte, deixara mesmo em muitos sujeitos rancorosos abafados, que não podiam irromper claramente, pelo temor que todos tinham de entrar em polêmica, de se bater um instante no jornalismo com um espirito forte como o d'elle (JULIO..., 1890, p. 1).

Acumulando outras inúmeras reprovações e apologéticas, A Carne ficou marcado na história da literatura brasileira como um romance controverso e obsceno. Segundo Marcelo Bulhões, na obra Leituras do desejo: o erotismo no romance naturalista brasileiro, a citada obra de Ribeiro foi considerada abominação moral e um perigo para a formação educacional dos jovens. Porém, fez sucesso entre o público leitor e teve várias edições mesmo depois da morte do escritor:

A carne, portanto vive de certa ambivalência, talvez como nenhum outro romance da literatura brasileira. Se na atualidade o romance é pelo menos admitido e incorporado aos estudos que promovem a relação da literatura com outras áreas, tais como a história, a sociologia e a antropologia, na época de sua publicação foi perseguido e, na corrente oposta, aplaudido e exaltado (BULHÕES, 2003, p. 29).

\section{Considerações finais}

No contexto em que Júlio Ribeiro viveu, a sexualidade deveria ser purificada pela igreja, clinicada pela medicina e vigiada pelas autoridades e famílias. $\mathrm{O}$ autor abordou assuntos tidos como tabus e ofensivos aos valores patriarcais do periodo, tais como: menstruação, sexo livre, desejos carnais, sexo fora do casamento, divórcio, entre outros, A Carne não deixa de ser, portanto, uma trama ficcional sobre uma mulher que vive seus desejos eróticos de forma intensa, explorando a sua sexualidade além do que era socialmente aceito, ou seja: para além da finalidade reprodutiva.

A mulher é historicamente pensada, desde os tempos de Eva, como a responsável pelo pecado e. consequentemente, expulsão do homem do paraíso. Esse estigma foi reforçado ao longo do tempo na cultura ocidental por diversos tratados, livros e imagens. Essa lógica coloca a condição feminina sempre em um patamar de inferioridade ao status masculino, pois a mulher é tida como um perigo constante para a racionalidade e integridade dos homens. Esse perigo precisa, portanto, ser afastado, disciplinado, sanado, purificado ou mesmo silenciado. Em outras palavras, a mulher é tida como a personificação de um objeto erótico (BATAILLE, 1987).

O escritor Júlio Ribeiro, por mais que tenha elaborado um romance repleto de temas transgressores, assim como outros representantes da seara naturalista, não conseguiu romper completamente com os padrões senhoriais de sua época. Contudo, a literatura erótica é quase sempre atrativa tanto para o público leitor, quanto para os críticos. Esse estilo de escrita costuma agremiar vários exemplos de obras que tiveram grande repercussão em diferentes épocas, porque questiona os usos do corpo humano, a sexualidade e os desejos, temas artísticos ainda considerados ofensivos para setores mais tradicionais da sociedade ocidental. Nesses termos, publicado em uma época repleta de manuais de etiqueta e comportamento feminino, A Carne constituiu uma relevante apologética da transgressão erótica. Porém, é preciso ainda frisar que se trata sempre de uma apologética feita do ponto de vista masculino.

\section{Referências}

AZEVEDO, Aluizio de. o Cortiço. Rio de Janeiro: Garnier, 1890.

BOSI, Alfredo. História concisa da literatura brasileira 43. ed. São Paulo: Cultrix, 2006.

BULHÕES, Marcelo. Leituras do Desejo: o erotismo no romance naturalista brasileiro. São Paulo: Editora da Universidade de São Paulo, 2003.

BATAILLE, Georges. O erotismo. Porto Alegre: L\&PM, 1987.

BEAUVOIR, Simone. O Segundo Sexo: a experiência vivida. 2. ed. São Paulo: Difusão Europeia do Livro, 1967.

BIBLIOGRAFIA. Jornal do Commercio, Rio de janeiro, ano $66, n^{\circ} 280$, out. de 1888 .

CAMINHA, Adolfo. A Normalista. Rio de Janeiro: Magalhães \& C., 1893

DIDI-HUBERMAN, Georges. La invención de la histeria: Charcot y la iconografia fotográfica de La Salpêtrière. Madrid: Cátedra, 2007

DEL PRIORE, Mary. História das mulheres no Brasil. 7. ed. São Paulo: Contexto, 2004.

FOUCAULT, Michel. História da sexualidade I: A vontade de saber. Rio de Janeiro: Edições Graal, 1988. 
MAGALHÃES, Valentim. Júlio Ribeiro. A Semana, Rio de Janeiro, v. I, Rio de Janeiro, 1885.

JULIO Ribeiro. In: O Mercantil. São Paulo, ano VII, n 1885, nov. de 1890.

RAGO, Margareth. Do cabaré ao lar: a utopia da cidade disciplinar (1890-1930). 2. ed. Rio de Janeiro: Paz e Terra, 1987

RIBEIRO, Júlio. A Carne. São Paulo: Teixeira \& Irmão Editores, 1888.

RIBEIRO, Júlio. Cartas Sertanejas. A Semana, Rio de Janeiro, v. I, 1885.

SILVEIRA, Célia Regina de. Fama e infâmia: Leituras do romance $A$ carne, de Júlio Ribeiro. ArtCultura, Uberlândia, v. 12, n. 21, p. 195-209, jul./dez. 2010.

\section{Joachin Azevedo Neto}

Doutor em História Cultural pela Universidade Federal de Santa Catarina (UFSC), em Florianópolis, SC, Brasil; professor da Universidade de Pernambuco (UPE), em Petrolina, PE, Brasil.

\section{Ediene Gomes da Silva}

Graduanda em História pela Universidade de Pernambuco (UPE), em Petrolina, PE, Brasil.

\section{Endereço para correspondência}

Joachin Azevedo Neto/ Ediene Gomes da Silva

Universidade de Pernambuco (UPE)

Rodovia BR 203, KM 02

Vila Eduardo, 56328900

Petrolina, PE, Brasil 